\title{
Study on Risk Factor Evaluation of Ischaemic Stroke Patients Admitted in a Tertiary Care Hospital: 100 Cases
}

\author{
Tazin Afrose Shah ${ }^{1,}$, Farhan Matin ${ }^{2}$, Anarul Islam ${ }^{3}$, Mahabubur Rahman ${ }^{4}$, Mohiduzzaman Tony ${ }^{5}$, \\ Md. Hyder Ali ${ }^{1}$
}

${ }^{1}$ Department of Medicine, Uttara Adhunik Medical College (UAMC), Dhaka, Bangladesh

${ }^{2}$ Department of Radiology and Imaging, Uttara Adhunik Medical College (UAMC), Dhaka, Bangladesh

${ }^{3}$ Department of Respiratory Medicine, Uttara Adhunik Medical College (UAMC), Dhaka, Bangladesh

${ }^{4}$ Department of Gastroenterology, Uttara Adhunik Medical College (UAMC), Dhaka, Bangladeshs

${ }^{5}$ Department of Surgery, Uttara Adhunik Medical College (UAMC), Dhaka, Bangladesh

Email address:

tazinshah@gmail.com (T. A. Shah)

${ }^{*}$ Corresponding author

\section{To cite this article:}

Tazin Afrose Shah, Farhan Matin, Anarul Islam, Mahabubur Rahman, Mohiduzzaman Tony, Md. Hyder Ali. Study on Risk Factor Evaluation of Ischaemic Stroke Patients Admitted in a Tertiary Care Hospital: 100 Cases. American Journal of Biomedical and Life Sciences.

Vol. 8, No. 6, 2020, pp. 225-230. doi: 10.11648/j.ajbls.20200806.16

Received: October 25, 2020; Accepted: November 12, 2020; Published: December 16, 2020

\begin{abstract}
Background: Stroke is defined as a sudden onset focal neurological deficit of vascular etiology and is a major cause of mortality and morbidity around the globe. The aim of this study was to find out the proportion of major risk factor or factors related in infarctive stroke cases. Methods: This hospital based descriptive cross sectional study was carried out in one hundred (100) ischemic stroke patients admitted in Medicine units associated with Neurology ward in Enam Medical College \& Hospital, Savar, Dhaka, Bangladesh during the period from January 2015 to September 2017. Permission for the study was taken from the mentioned departments and authorities. Subjects were selected in all age groups and both male and female patients to whom duration of illness were less than 72 hours. Results: Among all, $61 \%$ were male and $39 \%$ were female and male female ratio 1.56:1. The maximum number of patients $(36 \%)$ were in between $61-70$ years of age. Majority of the patients (40\%) came from middle class (TK. 7000-10,000/Month). A significant number of patients had high level of lipid profile e.g. Total cholesterol (>200 mg/dl) 73.33\%, LDL ( $>150 \mathrm{mg} / \mathrm{dl}) 60 \%$, TG (>150 mg/dl) $70 \%$. In many cases multiple risk factors were present. It was observed that hypertension was the most common major risk factor for stroke. Among the $60 \%$ of the hypertensive patients only $45 \%$ were controlled with treatment and $33.33 \%$ were uncontrolled with treatment and $21.66 \%$ did not take any medicine or measures. About $47 \%$ were smoker. Diabetes mellitus was detected in $26 \%$ of patients which is lower than hypertension and hyperlipidaemia. About $25 \%$ of patient had history of previous stroke and $20 \%$ patient had family history of stroke. Only $6 \%$ was alcoholic. Among the female patients $5 \%$ received oral pills. Conclusion: Hypertension is one of the major risk factors for the stroke. For the management and prevention of hypertension like stroke, we are recommending the following measures like Hypertension screening programme for early detection, management and follow up and increase awareness regarding hypertension and its complication. It should be controlled by personal motivation, anti-smoking campaign, banding of the smoking propaganda in the TV, Radio, News paper, poster, banner, leaflet etc. Ensure punishment for smoking in open public places and public transports.
\end{abstract}

Keywords: Ischemic, Stroke, Hypertension

\section{Introduction}

The term stroke can be defined as a focal neurological deficit of sudden onset, lasting for more than 24 hours, occurring as a result of non-traumatic pathological process involving the blood vessels of the brain, so the patient having a stroke is diagnosed as cerebrovascular disease/ accident (CVD/CVA). [1] 
WHO defined stroke as rapidly developed clinical signs of focal disturbance of cerebral function lasting for more than 24 hours or leading to death without any apparent cause other than vascular origin. [2] Stroke is third leading cause of death after heart disease and malignant disease. All over the world morbidity of stroke is also one of the important family, social and country burden as well as, which demands serious medical, socio-economic and rehabilitation issue. [3]

Cerebrovascular disease is predominating in the middle and late years of life. The incidence increases with age and the disease affects many people in their golden years. It is estimated to be responsible for $9.5 \%$ of all deaths and 5.1 million of the 16.7 million cardiovascular disease deaths. [4] In developed country there is an overall prevalence of stroke is 794 per 1000000 populations. In the United states it is estimated that more than 400000 patients are discharged each year from Hospital after a stroke. The age adjusted annual death rate from stroke is 116 per 100000 population in the USA and some 200 per 100000 in UK. It is higher in Afro Caribian population than Caucasian. It is uncommon below the age of 40 years and more common in male. Death rate from stroke is $25 \%$. [5] In Bangladesh adequate data is lacking on the incidence and mortality from stroke. Neverthless the gravity of the situation can easily be assessed by the high incidence of Hospital admission for similar illness.

Stroke occurs when blood vessels that carry blood to the brain suddenly becomes blocked or burst, preventing blood flow to the brain. [6]

On the basis of this pathophysiology, stroke is divided into infarcts (thrombotic or embolic) and haemorrhage. Ischaemia and infarction constitute $85-90 \%$ of the total stroke in the Western countries, while $10-15 \%$ are intracranial haemorrhage [7] but haemorrhages constitute a larger percentage in Asia. [8]

The appearance of the disease is influenced by many etilogical factors that is risk factors. Risk factors of stroke. [5] Cerebovascular disease can be divided into: Major risk factors include-1. Advanced age, 2. Arterial hypertension, 3. Cigarette smoking, 4. Diabetes mellitus, 5. Hyperlipidaemia, 6. Thrombotic manifestations. [5] Other risk factors are: 1. Positive family history. 2. High alcohol intake, 3. Oral contraceptives, 4 . Collagen vascular disease 5. Past history of CVD and 6. Obesity [3]. Life style factors such as: eating habits, obesity, smoking, alcoholism and physical and mental inactivity, increase the risk by many folds. [9]

Throughout the world, unfavorable trends in stroke risk factor profile, lack of prevention programs, misapplication or underutilization of stroke preventives lead to high stroke rates serve to widen the stroke prevention gap. This is unfortunate because stroke is well suited for prevention since it has a high prevalence economic cost, well-defined modifiable risk factors, and effective prevention measures. [10]

Regarding management of stroke, none can claim for the total cure of the disease but can prevent to some extent by early detection and proper management of risk factors.
In this hospital based descriptive (cross sectional) study effort will be made to identify in patients under study the risk factors present in context, to our compair either isolated or in combination, so that preventive measures can be taken earlier to reduce economic burden of this most disabling disease.

\section{Methods}

This hospital based descriptive cross sectional study carried out on one hundred (100) ischemic stroke patients admitted in Medicine units including Neurology ward in Enam Medical College \& Hospital, Savar, Dhaka, Bangladesh during the period from January 2015 to September 2017. Permission for the study was taken from the concerned departments and authorities. Following patients were included in the study: All infarctive stroke patients (confirmed by CT scan of brain) admitted in medicine units including Neurology, Patients of all age group and both male and female patients and duration of illness less than 72 hours. Case sampling was done consecutively. The initial Clinical diagnosis was made from detailed Clinical history from the patients or from his or her attendants and thorough Clinical examination especially neurological examination and examination of cardiovascular system. Subsequently it was confirmed by CT scan of brain. After an initial clinical diagnosis being established, further detailed history relevant to risk factors like hypertension, diabetes mellitus, ischemic heart disease, Cigarette smoking, hyperlipidaemia, obesity, family history, bleeding diathesis, connective tissue disorders, hyper viscosity syndrome, use of oral contraceptives, alcoholism and head trauma were taken from patient as well as his or her close family members. Informed consent had been taken from the patient or from the attendant of the patient for participation in the study. Routine investigations such as CBC with ESR, urine $\mathrm{R} / \mathrm{M} / \mathrm{E}$, blood glucose fasting and 2 hours after breakfast, fasting lipid profile, serum electrolytes, kidney function tests, chest x-ray, ECG were done in all cases. CSF study, Echocardiography, Antinuclear factor (ANF), C - reactive protein (CRP), cANCA, p-ANCA, MRI of the brain, MRA (Magnetic resonance angiography), lupus serology were done in selective cases. Patients were followed up during their stay in hospital to observe the outcome. Data of the patients were recorded in a predesigned case record form (C. R. F). After collection of data, results were analyzed and presented by simple statistical percentage and tabulated form.

\section{Results}

Table 1. Distribution of the study patients by demographic characteristics $(n=100)$.

\begin{tabular}{lll}
\hline Demographic characteristics & $\begin{array}{l}\text { Number of } \\
\text { patients }\end{array}$ & $\begin{array}{l}\text { Percentage } \\
(\%)\end{array}$ \\
\hline $\begin{array}{l}\text { Age (years) } \\
0-20\end{array}$ & 0 & 0 \\
\hline
\end{tabular}




\begin{tabular}{lll}
\hline Demographic characteristics & $\begin{array}{l}\text { Number of } \\
\text { patients }\end{array}$ & $\begin{array}{l}\text { Percentage } \\
\text { (\%) }\end{array}$ \\
\hline $21-30$ & 1 & 1 \\
$31-40$ & 6 & 6 \\
$41-50$ & 16 & 16 \\
$51-60$ & 24 & 24 \\
$61-70$ & 39 & 39 \\
$>70$ & 14 & 14 \\
Sex & 97 & 97 \\
Male & 61 & 61 \\
Female & 39 & 39 \\
M: F ratio & $1.56: 1$ & \\
Residence & & \\
Urban & 47 & 47 \\
Rural & 53 & 53 \\
Income status & & \\
Poor (<TK 3000/month) & 20 & 20 \\
Below average (TK. 3000-7000/month) & 32 & 32 \\
Average (TK. 7000-10000/month & 40 & 40 \\
Affluent (TK.>10000/month) & 4 & 4 \\
Occupation & & \\
Business & 21 & 21 \\
Service holder & 22 & 22 \\
Cultivator/Farmer & 14 & 14 \\
School Teacher & 6 & 6 \\
Worker & 6 & 6 \\
House wife & 24 & 24 \\
Others & 8 & 8 \\
\hline & & \\
\hline
\end{tabular}

The maximum number of patients $(36 \%)$ in these study were between $61-70$ years followed by $(24 \%)$ between the age of 51-60 years. The incidence of stroke shows male preponderance with ratio of male to female is $1.56: 1$. The majority of patients composed of house wife $(24 \%)$ among female, service holder (22\%) and business (21\%) among the study population. The above table shows that the average class group (40\%) comprises the major percentage of the patients, followed by below average class group (32\%). The above table shows that patients came from both urban and rural areas with slight rural (53\%) preponderance.

Table 2. Risk factors for ischaemic stroke $(n=100)$.

\begin{tabular}{lll}
\hline Risk factor & Number of patients & Percentage (\%) \\
\hline Hypertension & 60 & 60 \\
Smoking & 47 & 47 \\
Diabetes Mellitus & 26 & 26 \\
Hyperlipidaemia & 30 & 30 \\
Alcohol intake & 6 & 6 \\
Oral contraceptive & 5 & 5 \\
Past history of CVD & 25 & 25 \\
Family history of stroke & 20 & 20 \\
Obesity & 20 & 20 \\
Heart disease & 18 & 18 \\
\hline
\end{tabular}

In this study, hypertension $(60 \%)$ was found to be the most common risk factor. Next factor was smoking (47\%) followed by hyperlipidaemia (30\%), diabetes mellitus $(26 \%)$ and CVD (25\%).

Table 3. Distribution of the study patients by type of hypertension $(n=60)$.

\begin{tabular}{lll}
\hline Hypertension & Number of patients & Percentage (\%) \\
\hline Controlled & 27 & 45.0 \\
Uncontrolled & 20 & 33.33 \\
Not treated & 13 & 21.66 \\
\hline
\end{tabular}

In the above table, it shows that among the hypertensive patient only $45 \%$ controlled with treatment, $33.33 \%$ uncontrolled and $21.66 \%$ not treated at all.

Table 4. Descriptive statistics of lipid profile $(n=30)$.

\begin{tabular}{lll}
\hline Lipid profile (Fasting) & Number of patients & Percentage (\%) \\
\hline Total cholesterol $(>200 \mathrm{mg} / \mathrm{dl})$ & 22 & 73.33 \\
LDL $(>150 \mathrm{mg} / \mathrm{dl})$ & 18 & 60.0 \\
TG $(>150 \mathrm{mg} / \mathrm{dl})$ & 21 & 70.0 \\
HDL $(<35 \mathrm{mg} / \mathrm{dl})$ & 10 & 33.33 \\
\hline
\end{tabular}

Serum cholesterol is found above normal range in $73.33 \%$ (average)

Table 5. Relationship between physical activity and stroke $(n=100)$.

\begin{tabular}{lll}
\hline Physical activity & Number of patients & Percentage (\%) \\
\hline Harder worker & 8 & 8 \\
Moderate worker & 48 & 48 \\
Sedentary worker & 36 & 36 \\
\hline
\end{tabular}

The maximum number of patients in this study were moderate workers (48\%). Hard workers (8\%) composed the smallest group.

Table 6. Outcome of the patients during discharge $(n=100)$.

\begin{tabular}{lll}
\hline Status of the patients & Number of patients & Percentage (\%) \\
\hline Improved & 65 & 65 \\
Static & 15 & 15 \\
Death & 8 & 8 \\
DOR (Discharge on request & 12 & 12 \\
\hline
\end{tabular}

Out of total 100 patients, $65 \%$ improved, $8 \%$ died, $15 \%$ of the patients static and $12 \%$ patient discharged on request.

\section{Discussion}

The effect of various risk factors on stroke has been shown similar as well as considerable variation in different studies. In this study, peak age of incidence was between $61-70$ years $36 \%$, [Table 1] followed by $51-60$ years $24 \%$, 41-50 years $16 \%$ and above 70 years was $14 \%$. Many studies [11-14] reported the same age incidence between $5^{\text {th }}$ to $7^{\text {th }}$ decade in our country. It also coincided with the similar type of previous studies done by Kannel et al. [15], Chapman et al. [16], Dalal et al. [17] and Pessah et al. [18]. This study showed only $14 \%$ cases were above the age of 70 years. This finding strongly contradicted with the study conducted by WHO task force in 1989 and study by Aho et al, where the peak incidence of stroke was at above the age of 85 years. This discrepancy with the present study may be due to the normal life expectancy of 60 years in our country, which is less than that of the study group of WHO. In this study, $61 \%$ male and $39 \%$ were female i.e., male incidence is $22 \%$ higher than female and the ratio was $1.56: 1$ which is close to Thompson study. But a similar study [19] showed gross differences (M: $\mathrm{F}=4: 1)$ with higher male predominance.

In present study among the study people, hard worker $16 \%$, moderate worker $48 \%$ and sedentary life style $36 \%$. Majority of the patients were moderate workers. This results contradict with the study of Bashar [11], Manadir [12], Harsmen et al. [20], Keily et al [21] They found that moderate to hard work or physical activity among men had 
protective role against stroke. It needs further study but no significant protective role noted in women.

On the occupational basis (Table 1), businessmen in population $21 \%$, farmers $14 \%$ and house wives in female population $24 \%$ were significantly affected. Number of retired person simulates with that of Bashar study [11] resulting in extra burden on national economy. In most of the developed countries, retired persons mostly affected are $>65$ years. There were significant increase of strokes among the housewives which demand special attention to search for the causes and risk factors. In this study we found that hard workers and school teachers were less affected. High level of physical activity among male are protective against stroke relative to low level of physical activity. [21]

On the basis of socio-economic status (Table 1), the middle class (Monthly income TK. 7000-10000) comprise the majority (40\%) followed by lower middle class (Monthly income TK. 3000-7000) comprises 32\%. This result contradict with study by Hart CL et al. [22], study of Bashar [11] and study of Manadir. [12] It needs further detail evaluation. The higher income group $(>10,000 /$ month $)$ was only $4 \%$ and lower income group $(<3000 /$ month) was $20 \%$. From this study we get the impression that lower and higher income groups suffer from stroke but this may not be true in case of lower income group because many of the poor patients were not brought to hospital due to economic constrain, ignorance and poor transport facilities. In this study the lower economic group patients were admitted to the hospital came from outside the city area. The rich group of people was not taken into the hospital due to shortage of bed and other facilities. But this study also supported the study of Botania 1992, Bashar [11] and Manadir. [12] This study showed that (Table 1) study subjects were from both urban $(47 \%)$ and rural areas (53\%) with slight rural preponderance (6\%) which indicate that the incidence of stroke is common in both urban and rural population. This study was coincided with the study of Manadir [12], but strongly contradicted with the study of Bashar [11] which showed mainly urban predominance. The reason may be that study of Bashar was done in a private hospital with narrow catchment area, where mostly urban population can avail the hospital facilities mainly due to cost. [11] The present study was done in Chittagong Medical College Hospital where patients come from city as well as remote rural areas. This study also contradicted with the study of Engstrom et al. [23]

The present study showed that $47 \%$ were smoker. Multiple individual studies have demonstrated that the risk of stroke is increased among the cigarette smokers. Yano et al. [24] and Donnan et al. [25] had shown strong association between cigarette smoking and stroke. Similar study in Copenhagen [26] and Finland [27] had shown increased risk of stroke among smokers. New Zealand researcher reported that passive smoking significantly increases the risk of stroke among the non-smoker and long term ex-smoker. [25]

Present study showed that $26 \%$ (Table 2) stroke patients were diabetic. Diabetes mellitus has long been recognized as a risk factor for vascular disease as well as stroke. It is about double the risk of stroke compared with that of non-diabetics. [15] The Framingham study showed that $10-14 \%$ of stroke patients were diabetic. In BIRDEM by Latif et al. [25], a study on 165 cases of diabetic patients, all of them developed stroke in less than 10 years duration. The Copenhagen stroke study had shown that in 1135 acute stroke patients, $233(20 \%)$ were suffering from diabetes and diabetes mellitus influenced stroke in several aspects e.g. age, subtype, speed of recovery and mortality. [29] Oral /injectable (Hormone/implant) contraceptive: (Table 2) showed that $5 \%$ of the female patients gave history of taking oral pills and injections. Heinemann et al showed that there is slight increase in the relative risk of thromboembolic stroke in women currently using contraceptives compared with women not using them. He also concluded that the attributable risk is very small because the incidence in this age range is very small. The high dose estrogen pills carry higher risk than low dose formulation irrespective of type of the progestin. [30] There are no differences in risk of oral contraceptives of third and second generation, only first generation oral contraceptive seems to be higher risk.

In this study, $25 \%$ of the patients had previous history of some form of cerebrovascular disease (Table 3). This result contradicted with the study of Manadir [12] (9\%) and with the study of Aho et a. [2], Walker et al. [31] who showed that 4.3 to 33.5 percent of the patients suffering from acute stroke had a past history of one or more strokes.

In Table 3, showed that $20 \%$ patients of stroke had positive family history. This finding has little value to the incidence of stroke, because it is likely to be the result of an inherited tendency to one of the other risk factors. A positive family history was not an independent risk factor in multifactorious analysis but it was an excellent marker of the presence of other established vascular factors. [32] Another study has found a positive family history of stroke, diabetes mellitus, hypertension or ischaemic heart diseases in $13.1 \%$ of their stroke patients. [33]

In this study, 20\% patient were detected obese (Table 3). Peart SS et al. [34] had shown that the obesity has significant contribution to the risk of stroke of untreated patient of either sex. So findings in this study correlate well with above mentioned study. Honolulu heart program study [35] concluded that elevated body mass is associated with increased risk of thromboembolic stroke in non-smoking men and in older middle age people. A 20 years follow up study in Scotland [22] showed that although participant with highest body mass index had highest stroke rate. Rhados and Kagan 1980 studied 8006 younger Japanese men and concluded that obesity was positively related with stroke incidence. So, the relationship between obesity and stroke needs further evaluation. Only $6 \%$ (Table 3 ) of this study sample had history of alcohol consumption. This lower incidence of alcohol intake of our study is related to socio-cultural and religious inhibition. But there is definite relation between alcohol consumption and the occurrence of stroke. Macfarlane et al. [36] concluded that heavy drinking increased the incidence of stroke compared to non-drinker or occasional drinker. This study failed to determine the direct relationship. 
In this study (Table 3) $18 \%$ cases had association with heart disease. Similar study by Hayee et al. [37] on 427 stroke patients found $29.66 \%$ were suffering from different heart diseases. In the present study, out of -18 patients, 12 $(66.66 \%)$ had myocardial infarction/ischaemia, 1 (5.55\%) had valvular heart disease, $5(27.77 \%)$ had heart failure. Ischemic heart disease, heart failure definitely augment the risk of strokes. [38] A study done by Macfarlane PW et al 1991 [36] in Britain over middle aged British men, it has been shown that men with definite evidence of previous myocardial infarction had four fold increase risk of strokes compared to men with no pre-existing ischemic heart disease. Bundlie [39] revealed that $24 \%$ of stroke patients had evidence of recurrent myocardial infarctions. In the present study no stroke due to congenital heart disease was found.

In this study (Table 3) hypertension emerges as the important and most common risk factor in ischaemic stroke. Out of 60 cases $(60 \%)$ only 27 patients were controlled with antihypertensive drugs and rest 20 were uncontrolled with antihypertensive drugs, 13 patients were not treated at all. This study was correlated with similar type of study done by Hayee et al. [37] (52.11\%), Mannan and Alamgir [19] (58\%), Latif et al [28] (50.03\%). Similar studies in some Asian countries also correlate with the present study. Wong [40] studied 3670 hospital admitted stroke patients in several South East Asian countries and found 64\% hypertensive. In prospective study in Shanghai, China by Ross RK et al. [41], hypertension was the most important risk factor for stroke. The result correlates with the study of urban population of Calcutta in 2001, where hypertension was found to be the most significant risk factor. In the Japanese centre the association of hypertension was about $75 \%$ and in Moscow and in Ulan Bator it was even higher. [2, 22]

In the present study (Table 3) non compliance to the treatment of hypertension was quite high $33.33 \%$. Chowdhury SGM et al. [13] in their study of 78 known hypertensive patients who suffered from stroke, had shown that 92.54 percent were taking drugs irregularly. Raised serum cholesterol is an important risk factor in ischaemic heart disease but its relation with stroke was not clear. [42] In this study, out of 30 patients (Table 4) total cholesterol was raised in 22 patient $(73.33 \%)$, LDL raised in 18 patient $(60 \%)$, TG raised in 21 patient $(70 \%)$ and decreased HDL in 10 patient $(33.33 \%)$. This finding was nearer to the findings of Hayee et al. [37] In their study they found $19.07 \%$ of total cases of strokes had elevated serum total cholesterol. But present study has contradicted with the study of Bashar [11] (15\%) and Mandir (12\%). [12] However, the relationship between stroke and hyperlipidaemia needs further research. Finally (Table 6), out of 100 patients $65 \%$ improved, $15 \%$ were in static condition, $8 \%$ expired and $12 \%$ were discharged on request.

\section{Conclusion}

Stroke is one of the major causes of not only morbidity and mortality but also exerts enormous burden to the economy of the country. This devastating and dreadful condition not only affect the patient but also their family and the society. Study reveals that hypertension is the number one major risk factor for the stroke. Smoking is the second most important major risk factor for stroke.

a. Hypertension screening programme for early detection, management and follow up.

b. Smoking is the second most important major risk factor for stroke. It should be controlled by personal motivation, anti-smoking campaign, banding of the smoking propaganda in the TV, Radio, Newspaper, poster, banner, leaflet etc. Ensure punishment for smoking in open public places and public transports.

c. Diabetes mellitus should be properly screened, diagnosed and managed.

d. Hyperlipidaemia should be properly emphasized and evaluated. It demands further study to correlate with stroke.

Stressful life style among the lower middle class stroke patients in our country needs extensive research. Finally it is clear that the best way of facing stroke is prevention and controlling the modifiable risk factors and search for new emerging risk factors which are contributing in stroke pathogenesis.

\section{References}

[1] Bamford J. Clinical examination in diagnosis and subclassification of stroke. The lancet. 1992 Feb 15; 339 (8790): 400-2.

[2] Aho K, Harmsen P, Hatano S, Marquardsen J, Smirnov VE, Strasser T. Cerebrovascular disease in the community: results of a WHO collaborative study. Bulletin of the World Health Organization. 1980; 58 (1): 113.

[3] Kistler JP, Rooper AA, Martin JB. Cerebrovascular diseases Isselbacher KJ, Wilson JD, Braunwald $\mathrm{E}$, et al, editors. Harrison's Principles of Internal Medicine, $13^{\text {th }}$ ed. New York: McGraw Hill Inc. 1994; 2233-2255.

[4] Swartz MN. Cerebrovascular disease in Cecil Textbook of Medicine, $21^{\text {st }}$ ed. Goldman and Bennett (eds). W. B Saunders Company. 2001; 324: 1645-1654.

[5] Clarke CRA. Cerebrovascular disease and stroke in Kumar \& Clark Clinical Medicine, $5^{\text {th }}$ ed. Parveen K, Clark M (eds). W. B. Saunders Company. 2002; 1163-1173.

[6] Mc Caron OM, Delong D, Alberts MJ. APO-E genotype as a risk factor for ischemic cerebrovascular disease. Neurology. 1994; 44: 626-634.

[7] Benson RT, Sacco RL. Stroke prevention: hypertension, diabetes, tobacco, and lipids. Neurologic clinics. 2000 May 1; 18 (2): 309-19.

[8] Poungvarin N. Stroke in the developing world. The Lancet. 1998 Oct 1; 352: S19-22.

[9] Bronner LL, Kanter DS, Manson JE. Primary prevention of stroke. New England Journal of Medicine. 1995 Nov 23; 333 (21): 1392-400. 
[10] Elkind MS, Sacco RL. Stroke risk factors and stroke prevention. InSeminars in Neurology 1998 Dec 1 (Vol. 18, No. 4, pp. 429-440). Thieme Medical Publishers.

[11] Bashar A. A dissertation on "Study of risk factors for stroke" 1995; 78-90.

[12] Hossain A, Manadir. Analysis of risk factor for stroke in Hospitalized patient in a Medical College Hospital. 2001.

[13] Roy PK, Arif SM, Alam MR, Khan FD, Ahmad Q, Chowdhury SG. Stroke in patients having inadequate or irregular antihypertensive therapy. Bangladesh Medical Research Council bulletin. 1990 Dec; 16 (2): 52-7.

[14] Sayeed Mohammad Arif. A dissertation on study on risk factor for stroke in Bangladesh. 1993; 55.

[15] Kannel WB, Gordon T, Dawber TR. Role of lipids in the development of brain infarction: the Framingham study. Stroke. 1974 Nov 1; 5 (6): 679-85.

[16] Chapman JM, Reeder LG, Borun ER, Clark VA, Coulson AH. Epidemiology of vascular lesions affecting the central nervous system: The occurrence of strokes in a sample population under observation for cardiovascular disease. American Journal of Public Health and the Nations Health. 1966 Feb; 56 (2): 191-201.

[17] Dalal PM, Shah PM, Aiyar RR, Kikani BJ. Cerebrovascular Diseases in West Central India. Br Med J. 1968 Sep 28; 3 (5621): 769-74.

[18] Pessah-Rasmussen H, Engström G, Jerntorp I, Janzon L. Increasing stroke incidence and decreasing case fatality, 1989-1998: a study from the stroke register in Malmo, Sweden. Stroke. 2003 Apr 1; 34 (4): 913-8.

[19] Alamgir SM, Mannan MA. Cerebrovascular disease (A report of 53 cases). Bangladesh Med Res Coun Bull. 1975; 1: 45-50.

[20] Harmsen P, Rosengren A, Tsipogianni A, Wilhelmsen L. Risk factors for stroke in middle-aged men in Göteborg, Sweden. Stroke. 1990 Feb 1; 21 (2): 223-9.

[21] Kiel Y DK, Hole, Smith GD. Comparison of risk factors for stroke incidence and stroke risk. Am J Epidemiol. 1994; 140: 608-620.

[22] Hart CL, Hole DJ, Smith GD. Comparison of risk factors for stroke incidence and stroke mortality in 20 years of follow-up in men and women in the Renfrew/Paisley Study in Scotland. Stroke. 2000 Aug 1; 31 (8): 1893-6.

[23] Engstrom G, Jerntorp I, Pessah-Rasmussen H, Hedblad B, Berglund G, Janzon L. Geographic distribution of stroke incidence within an urban population: relations to socioeconomic circumstances and prevalence of cardiovascular risk factors. Stroke. 2001 May; 32 (5): 1098-103.

[24] Abbott RD, Yin Y, Reed DM, Yano K. Risk of stroke in male cigarette smokers. New England journal of medicine. 1986 Sep 18; 315 (12): 717-20.

[25] Donnan G, Adena M, O'Malley H, Mcneil J, Doyle A, Neill G. Smoking as a risk factor for cerebral ischaemia. The Lancet. 1989 Sep 16; 334 (8664): 643-7.

[26] Boysen G, Nyboe J, Appleyard M, Sørensen PS, Boas J, Somnier F, Jensen G, Schnohr P. Stroke incidence and risk factors for stroke in Copenhagen, Denmark. Stroke. 1988 Nov $1 ; 19$ (11): 1345-53.
[27] Salonen JT, Puska P, Tuomilehto J, Homan K. Relation of blood pressure, serum lipids, and smoking to the risk of cerebral stroke. A longitudinal study in Eastern Finland. Stroke. 1982 May 1; 13 (3): 327-33.

[28] Latif ZA, Zaman SM, Barua A, Ahad A, Rahim SA. Study of stroke between normotensive and hypertensive NIDDM cases in BIRDEM, Dhaka. Bangladesh journal of Neuroscience. 1990; 6: 52-9.

[29] Iemolo F, Beghi E, Cavestro C, Micheli A, Giordano A, Caggia E. Incidence, risk factors and short-term mortality of stroke in Vittoria, southern Italy. Neurological sciences. 2002 Apr 1; 23 (1): 15-21.

[30] Farley TM, Meirik O, Chang CL, Poulter NR. Combined oral contraceptives, smoking, and cardiovascular risk. Journal of Epidemiology \& Community Health. 1998 Dec 1; 52 (12): 775-85.

[31] Walker AE, Robins M, Weinfeld FD. The National Survey of Stroke. Clinical findings. Stroke. 1981; 12 (2 Pt 2 Suppl 1): I13-44.

[32] Morrison AC, Fornage M, Liao D, Boerwinkle E. Parental history of stroke predicts subclinical but not clinical stroke: the Atherosclerosis Risk in Communities Study. Stroke. 2000 Sep 1; 31 (9): 2098-102.

[33] Sigurdsson G, Sigfusson N, Thorsteinsson, Olafsson O, Davidson D, Samielson. Screening for health risks. Acta Med Scand15. 1983; 45-50.

[34] Macfarlane TV, Pigazzani F, Flynn RW, Macdonald TM. The effect of indapamide versus bendroflumethiazide for primary hypertension: a systematic review. British journal of clinical pharmacology. 2018 Oct 12; 296: 1565-70.

[35] Abbott RD, Behrens GR, Sharp DS, Rodriguez BL, Burchfiel CM, Ross GW, Yano K, Curb JD. Body mass index and thromboembolic stroke in nonsmoking men in older middle age. The Honolulu Heart Program. Stroke. 1994 Dec 1; 25 (12): $2370-6$.

[36] Shaper AG, Phillips AN, Pocock SJ, Walker M, Macfarlane PW. Risk factors for stroke in middle aged British men. Bmj. 1991 May 11; 302 (6785): 1111-5.

[37] Hayee A, Haque A, Anwarrullah AKM, Akhter N. Analysis of risk factor of stroke in 472 cases. Bangladesh Journal of Neuroscience. 1998; 14 (2): 41-54.

[38] Thompson SBN and Morgan. Epidemiology of stroke. In. Occupational therapy for stroke rehabilitation, $1^{\text {st }}$ ed. Chapman and Hall, London. 1990; 1-14.

[39] Budlie SR. Ischemic stroke. Postgrad Med. 1991; 90: 56-63.

[40] Wong KS. International Prospective Hospital-based study of acute stroke incidence. Lancet. 1998; 352.

[41] Ross RK, Yuan JM, Henderson BE, Park J, Gao YT, Yu MC. Prospective evaluation of dietary and other predictors of fatal stroke in Shanghai, China. Circulation. 1997 Jul 1; 96 (1): 50-5.

[42] Marmot MG, Poulter NR. Primary prevention of stroke. The Lancet. 1992 Feb 8; 339 (8789): 344-7. 